\title{
Absolute and Relative Scaling of Power Transformers using Grey Incidence and Relational Analysis
}

\author{
Vikal R. Ingle \\ B.D.College of Engg.,Sevagram \\ Wardha(MS), India
}

\author{
V. T. Ingole, PhD \\ Dr.Rajendra Gode Institute of \\ Research \& Tech., \\ Amravati(MS),India
}

\begin{abstract}
Health or criticality index of power transformer is computed by utilizing the heuristic knowledge, employed on massive parametric data. For assessment purpose, it is unreasonable to collect the huge data of monitoring and test equipments frequently. As a first information source, dissolved gases-inoil is secured in interpreting the transformer condition. The major seven dissolved gases are referred as key gases in IEEE/IEC gas guide. Dissolved Combustible Gases (TDCG) standard for state assessment uses caution levels of key gases for condition judgment. The phenomenon of dissolved-gas-inoil observed analogous to grey system, as one can use this partial information about transformer for health index determination. Grey system theory deals with the incomplete information in system analysis. The objective of this paper is, to evaluate the health index of transformers by means of Grey Incidence Analysis (GIA) and Grey Relational Analysis (GRA) for absolute and relative scaling respectively. Synthetic degree of GIA is employed for absolute scaling, where the test samples are compared with industry standard. However, test samples are compared without applying any standard model in GRA by means of approaching degree. The assessment results from grey analysis are further examined by Adaptive Neuro-Fuzzy Inference System (ANFIS) and Network Fitting (NF) tool. The proposed measurement is promising in priority based maintenance activities of power transformer.
\end{abstract}

\section{General Terms}

Power Transformer state assessment, Grey system Theory

\section{Keywords}

Key gases, DGA, Health Index of PT, Grey Incidence Analysis, Grey Relational Analysis, Absolute and Relative scaling.

\section{INTRODUCTION}

Power Transformer (PT) is one of the significant devices observed in every substation, typically a design life of 20-35 years. However, life extension of transformer as long as 60 years is possible with proper maintenance. Deformation in transformer observed due to thermal, electrical, chemical and mechanical stresses [1]. Hence fault diagnosis becomes increasingly important to keep power systems in normal operation [2]. Several monitoring and testing equipment are preferred to identify the health status of transformer [3]. The health or criticality indices are commonly determined through supervision of various components of transformer [4]. These indices are the effective measures for transformers state ranking [5]. Some technical service groups assign score or condition factor to every component of transformer in preparing the rank within test samples [6-8]. The selection of correct assessment method can only give better health or criticality index from the measured factors. Although, frequent data accumulation from all disseminated test equipment is unrealistic, as some test only conceded by shutting down the operation of transformer. As an alternative, Dissolved Gas Analysis (DGA) is a safe technique of interpretation. The characteristic gases observed in the oil include hydrogen, methane, acetylene, ethylene, ethane, carbon monoxide and carbon dioxide. These seven gases are referred as 'key gases' and utilized for DGA. All the information related to DGA is contained in gas guides such as ANSI/IEEE C57.104 ${ }^{\mathrm{TM}}$ (Revision of IEEE std.) and IEC 60599. Total Dissolved Combustible Gases (TDCG) criteria, mentioned in gas guide [9-10] for condition judgment is shown in Table-1.

Several assessment methods as well as techniques are tried on gas data and some associated parameters of the power transformer. Soft computing techniques such as ANN [11], Neuro-Fuzzy Inference System [12], Fuzzy logic [5, 13] and Genetic algorithm [14] are effectively used in deducing the diagnostics and ranking of transformers. These soft computing methods need ample data of system's input/output. Results drawn from these computing have shown certain degree of success although the assessment methods were found indistinctive. Applying the statistical or model-free methods can hardly achieve useful solutions. In addition, frequent collection of all the parametric data from power transformer is unrealistic. Hence the assessment method which deals in partial information is requisite for analysis.

Grey theory proposed by J. L. Deng in 1982, deals in partial information i.e. distribution free samples of small size [15] for system analysis. A complete description of grey systems theory on the axioms of uncertainty and grey cognitive principles [16] are strongly treated in mathematical formats. Several methods such as grey incidence analysis, grey sequence generations, and grey $\operatorname{GM}(1,1)$ model are commonly used for evaluation, prediction, decision-making, control and optimization[17]. A verity of Grey methods is also introduced in the field of power transformer analysis [18-23]. This paper concerned with the two different assessment methods of grey theory i.e. GIA and GRA, employed on key gas data set for transformer health index calculation and scaling. 
Table 1: IEEE specified Gas levels and conditions of transformer

\begin{tabular}{|l|l|l|l|l|l|l|l|l|}
\hline Status & $\mathbf{H}_{\mathbf{2}}$ & $\mathbf{C H}_{\mathbf{4}}$ & $\mathbf{C}_{\mathbf{2}} \mathbf{H}_{\mathbf{2}}$ & $\mathbf{C}_{\mathbf{2}} \mathbf{H}_{\mathbf{4}}$ & $\mathbf{C}_{\mathbf{2}} \mathbf{H}_{\mathbf{6}}$ & $\mathbf{C O}$ & $\mathbf{C O}_{\mathbf{2}}$ & TDCG \\
\hline Condition-1 & $<100$ & $<120$ & $<35$ & $<50$ & $<65$ & $<350$ & $<2500$ & $<720$ \\
\hline Condition-2 & $101-700$ & $121-400$ & $36-50$ & $51-100$ & $66-100$ & $351-570$ & $2500-4000$ & $721-1920$ \\
\hline Condition-3 & $701-1800$ & $401-1000$ & $51-80$ & $101-200$ & $101-150$ & $571-1400$ & $4001-10000$ & $1921-4630$ \\
\hline Condition-4 & $>1800$ & $>1000$ & $>80$ & $>200$ & $>150$ & $>1400$ & $>10000$ & $>4630$ \\
\hline
\end{tabular}

\section{GREY INCIDENCE AND}

\section{RELATIONAL ANALYSIS}

Assuming the behavioral sequence of a factor $x_{i}$,

$x_{i}(\mathrm{k})=\left(x_{i}(1), x_{i}(2), \ldots \ldots \ldots \ldots . . . x_{i}(\mathrm{n})\right)$ and

$D i$ a sequence operator satisfying

$X_{i} D_{i}=\left(x_{i}(1) d_{1}, x_{i}(2) d_{1}, \ldots, x_{i}(n) d_{1}\right)$

Definition1: Assume that $X$ is the set of all factors involved in a study of a system, and $D$ the set of all grey incidence operators. Whereas, $(X, D)$ is called the space of grey incidence. Some useful sequence operators and corresponding transform are given as follows.

Table 2: Data normalization operators

\begin{tabular}{|c|l|l|}
\hline $\begin{array}{c}\text { Sr. } \\
\text { No. }\end{array}$ & $\begin{array}{l}\text { Sequence } \\
\text { operators }\end{array}$ & Transform \\
\hline 1. & Initialing & $x_{i}(k) d_{1}=\frac{x_{i}(\mathrm{k})}{x_{i}(1)}$ \\
\hline 2. & Averaging & $x_{i}(k) d_{2}=\frac{x_{i}(k)}{\overline{X_{i}}}$, \\
\hline 3. & Interval & $x_{i}(k) d_{3}=\frac{\left.x_{i}(k)-\begin{array}{c}\min \\
\max _{k}\left\{x_{i}(k)\right\} \\
k\end{array} x_{i}(k)\right\}-\min _{k}\left\{x_{i}(k)\right\}}{}$ \\
\hline 4. & Reversing & $x_{i}(k) d_{4}=1-x_{i}(k)$ \\
\hline 5. & Reciprocating & $x_{i}(k) d_{5}=1 / x_{i}(k)$ \\
\hline 6. & zero starting point & $x_{i}(k) d=x_{i}(k)-x_{i}(1)$ \\
\hline
\end{tabular}

Proposition: Assume that the images of the zero starting point of two behavioral sequences

$x_{i}^{0}=\left(x_{i}^{0}(1), x_{i}^{0}(2), \ldots \ldots \ldots \ldots \ldots, x_{i}^{0}(n)\right)$ and $x_{j}^{0}=$

$\left(x_{j}^{0}(1), x_{j}^{0}(2), \ldots \ldots \ldots \ldots \ldots, x_{j}^{0}(n)\right)$

Let, $S_{i}-S_{j}=\int_{1}^{n}\left(x_{i}^{0}-x_{j}^{0}\right) d t$

Then following hold true.

(a) If $x_{i}^{0}$ is always above $x_{j}^{0}$, then $S_{i}-S_{j} \geq 0$;

(b) If $x_{i}^{0}$ is always underneath $x_{j}^{0}$ is always then $S_{i}-S_{j} \leq 0 ;$ and

(c) If $x_{i}^{0}$ and $x_{j}^{0}$ alternate their positions, the sign of $S_{i}-S_{j}$ is not fixed.

Definition 2: Assuming two sequences $X_{i}$ and $X_{j}$ of the same length, $S_{i}$ and $S_{j}$ is defined as in preposition, then $\varepsilon i j=$ $\frac{1+|S i|+|S j|}{1+|S i|+|S j|+|S i-S j|}$ is called the absolute degree of grey incidence of $X_{i}$ and $X_{j}$.

Definition 3: $X_{i}$ and $X_{j}$ are two sequences as that of def.1 with the initial values being zero, $\chi_{i}{ }^{\prime}$ and $X_{j}{ }^{\prime}$ are the initial image of $x_{i}$ and $x_{j}$ respectively. Then, the absolute degree of grey incidence of $X_{i}$ 'and $X_{j}$ ' is called the relative degree of grey incidence, denoted as $\boldsymbol{r}_{\boldsymbol{i} \boldsymbol{j}}$ and $0<\boldsymbol{r}_{\boldsymbol{i j}}<1$.

Definition 4: When general relationship of closeness between sequences is considered, then incidence degree is expressed using, $\boldsymbol{\rho}_{\boldsymbol{i j}}=\boldsymbol{\theta} \boldsymbol{\varepsilon} \boldsymbol{i} \boldsymbol{j}+(\mathbf{1}-\boldsymbol{\theta}) \boldsymbol{r}_{\boldsymbol{i j}}$ and denoted as synthetic degree of grey incidences. Typically $\theta$ is set to 0.5 , but to realize the relationship between some absolute quantities, greater values can also be useful. If the priority is to observe the rate of change, smaller values of $\theta$ is often employed [24]. Absolute, relative and synthetic matrixes of grey incidences are achieved using system characteristic and relevant factors

as follows-

IEEE specified key gases caution levels (Y1 to Y3) are used here as system characteristic and key gas samples of five transformers (X1 to X5) are tested through three different degrees of grey incidences.

Table 3: key gas Caution levels and test samples

\begin{tabular}{|l|l|l|l|l|l|l|l|l|}
\hline $\begin{array}{l}\text { Key } \\
\text { Gases }\end{array}$ & \multicolumn{2}{|c|}{$\begin{array}{l}\text { System Chart. } \\
\text { (IEEE std.) }\end{array}$} & \multicolumn{6}{l|}{$\begin{array}{l}\text { Sequences of Relevant } \\
\text { factors }\end{array}$} \\
\cline { 2 - 10 } & Y1 & Y2 & Y3 & X1 & X2 & X3 & X4 & X5 \\
\hline $\mathrm{H}_{2}$ & 100 & 700 & 1800 & 53 & 12 & 1 & 12 & 1 \\
\hline $\mathrm{CH}_{4}$ & 120 & 400 & 1000 & 49 & 325 & 19 & 8778 & 73 \\
\hline $\mathrm{CO}$ & 350 & 570 & 1400 & 748 & 12 & 140 & 317 & 124 \\
\hline $\mathrm{CO}_{2}$ & 2500 & 4000 & 10000 & 6021 & 787 & 1879 & 2959 & 66260 \\
\hline $\mathrm{C}_{2} \mathrm{H}_{4}$ & 50 & 100 & 200 & 2824 & 1 & 1 & 11900 & 1 \\
\hline $\mathrm{C}_{2} \mathrm{H}_{6}$ & 65 & 100 & 150 & 514 & 3 & 57 & 4834 & 88 \\
\hline $\mathrm{C}_{2} \mathrm{H}_{2}$ & 35 & 50 & 80 & 31 & 108 & 1 & 18 & 1 \\
\hline
\end{tabular}

The Absolute matrix of Incidences estimation is as follows-

$\mathrm{A}=[\varepsilon i j]_{3 \times 5}=\left(\begin{array}{lllll}0.6304 & 0.7186 & 0.9096 & 0.5444 & 0.5191 \\ 0.5687 & 0.9148 & 0.8216 & 0.5234 & 0.5101 \\ 0.6476 & 0.6930 & 0.8617 & 0.5503 & 0.5217\end{array}\right)$

The images of Zero stating points of system characteristics and relevant factors are calculated to get the coefficients of Relative matrix of incidences-

$$
\mathrm{B}=\left[\mathrm{r}_{\mathrm{ij}}\right]=\left(\begin{array}{ccccc}
0.5696 & 0.6391 & 0.5062 & 0.5054 & 0.5001 \\
0.5064 & 0.5129 & 0.5005 & 0.5005 & 0.5000 \\
0.5056 & 0.5112 & 0.5005 & 0.5004 & 0.5000
\end{array}\right)
$$

The Synthetic matrix of incidences with resolving factor i.e. $\theta=0.5$ is,

$$
\begin{aligned}
& \mathrm{C}=[\boldsymbol{\theta} \mathrm{A}+(\mathbf{1}-\boldsymbol{\theta}) \mathrm{B}]=\left[\boldsymbol{\theta} \varepsilon \boldsymbol{i j}+(\mathbf{1 - \theta}) \boldsymbol{r}_{\boldsymbol{i j}}\right]
\end{aligned}
$$

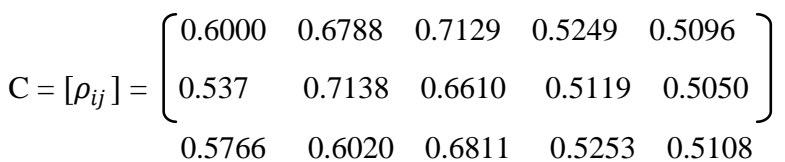

The results from synthetic matrix indicate that $\mathrm{Y}_{1}$ is the quasi- preferred system $\left(\right.$ Sum of Row $\left._{1}=3.0262\right)$ characteristic and ranking of relevant factors (key gas test samples of transformers) - $\mathbf{X}_{3} \geq \mathbf{X}_{2} \geq \mathbf{X}_{1} \geq \mathbf{X}_{4} \geq \mathbf{X}_{5}$

Where, test sample $X_{3}$ (sum of column $n_{3}=2.055$ ) is healthy compare to sample $\mathrm{X}_{5}(1.5254)$, indicates immediate attention for transformer no.5. 
Synthetic degree (SD) of grey incidence is a numerical index that describes the overall relationship of closeness in the interval of 0.5 to 1 . Hence, possible health judgment criterion for absolute scaling of transformers using synthetic degree of incidence is -

Table 4: Absolute Scaling Criterion

\begin{tabular}{|l|l|}
\hline Absolute Scaling & State of Transformer \\
\hline DGI $>=0.90$ & Healthy \\
\hline DGI $>=0.80$ & Abs. Normal \\
\hline DGI $>=0.70$ & Normal \\
\hline DGI $>=0.60$ & Slight fault \\
\hline DGI $>=0.50$ & Serious fault \\
\hline
\end{tabular}

\section{GREY RELATIONAL ANALYSIS}

To apply GRA, input attributes need to satisfy three conditions given as-

(i) The attributes not less than a magnitude of two.

(ii) All attributes must be of the same type i.e. benefit, cost, or optimization of a specific value.

(iii) All attributes have the same measurement scale, if uses quantitative scale (same unit or no unit).

All the above conditions are referred as scaling (for the order of magnitude), polarization (for the attribute type), and nondimension (for the measurement scale). The GRA algorithm is specified as follows:

\section{Constructing standard pattern (bull's eye)}

Assume $W_{i}$ is the state model- $i$, and $W(k)$ is the state parameter of sequence-k for constructing the model

- Standard state model- $W_{0}$ :

Assume $W_{i}$ is the multi-polarity criteria sequence:

$W_{i}=\left\{W_{i}(1), W_{i}(2), \ldots \ldots \ldots \ldots, W_{i}(\mathrm{n})\right\}$

$\forall W_{i}(\mathrm{k}) \in W_{i}=>\mathrm{k} \in \mathrm{K}=\{1,2, \ldots, \mathrm{n}\}, \mathrm{i} \in \mathrm{I}=\{1,2, . ., \mathrm{m}\}$

Define $\omega(\mathrm{k})$ as specification model sequence:

$W i(K)=(W 1(k), W 2(k), \ldots \ldots . W m(K))$

$\forall W(k) \in=>W(k) \Rightarrow>\mathrm{i} \in \mathrm{I}=\{1,2, . ., \mathrm{m}\}$

Suppose POL (max), POL (min), POL (mem) refers to the maximum polarity, the minimum polarity and the medium polarity respectively.

i) While POL $W i(K)=\operatorname{POL}(\max )$, then $W_{0}(\mathrm{k})=\max W i(K)$,

ii)While POL $W i(K)=\operatorname{POL}(\min )$, then $W_{0}(\mathrm{k})=\min W i(K)$,

iii)While POLWi $(K)=\mathrm{POL}(\mathrm{mem})$, then $W_{0}(\mathrm{k})=\operatorname{avg} W i(K)$,

Where, $W i(K) \in W(K)$ for all criteria and the standard pattern sequence will be-

$W_{0}=\left\{W_{0}(1), W_{0}(2), \ldots \ldots, W_{0}(\mathrm{n})\right\}$ also called as target heart.

\section{- Transforming grey target}

Assume that $\mathrm{T}$ is a grey target transform, then

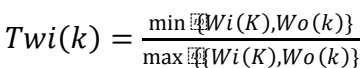

Where, $X_{0}$ refers to the standard bulles eye and $X_{0}(\mathrm{k}) \in X_{0}$ $\Rightarrow X_{0}=T_{w 0} ;$ and, $T_{w 0}=X_{0}=(1,1 \ldots 1)$

\section{- Calculate grey bull's eye coefficients and Target heart degree}

The coefficient of target heart degree calculate through

$$
\gamma\left(x_{0}(k), x_{i}(k)\right)=\frac{\left\{\min _{i} \max _{k} \Delta o i(k)+\rho \max _{i} \max _{k} \Delta o i(k)\right\}}{\Delta o i(k)+\rho \max _{i} \max _{k} \Delta o i(k)}
$$

$\rho^{\text {ee }}$ is the resolving coefficient, $\rho \in[0,1]$, generally $\rho=0.5$; $\Delta$ oi (k) shows the grey relational different information space between evaluated sequence $\omega \mathrm{i}$ and target heart $\omega 0$.

$\Delta O_{i}(\mathrm{k})=\left|x_{0}(k)-x_{i}(k)\right|=\left|1-x_{i}(k)\right|$;

$\Delta O_{i}(\min )=\min _{i} \min _{k} \min . \Delta o_{i k} ; \quad \Delta O_{i}(\max )=$ $\max _{i} \max _{k} \min . \Delta o_{i k}$;

Taking the average of the grey relation coefficient to Target heart degree (Jianpo Li et.al.2009) by applying -

$$
\left.\gamma\left(X_{0}, X_{i}\right)\right)=\frac{1}{n} \sum_{k=1}^{n} \gamma\left(x_{0}(k), x_{i}(k)\right) \ldots \ldots(3)
$$

The approaching degree (AD) by means of GRA will rank the alternatives into nine interval levels as follows: $[0.9,1.0] ;[0.8,0.9] ;[0.7,0.8] ;[0.6,0.7] ; \quad[0.5,0.6] ; \quad[0.4,0.5] ;$ $[0.3,0.4] ;[0.2,0.3] ;[0.1,0.2]$.

Suppose equal weights are considered for every attributes then $\rho=0.5$, and

$$
\gamma\left(\mathrm{x}_{0}, \mathrm{x}_{\mathrm{i}}\right) \geq \frac{\rho}{\rho+1} \quad=0.3333
$$

Based on above basic principle, the pros degree of each alternative separated as: $[0.9,1.0] ;[0.8,0.9] ;[0.7,0.8] ;[0.6$, $0.7] ;[0.5,0.6] ;[0.4,0.5] ;[0.33333,0.4]$. Therefore, these seven intervals established an important relationship for state assessment. The relative scaling of transformers refer to approaching degree is possible using the following criterion shown in Table-5.

Table 5: Relative scaling criterion

\begin{tabular}{|l|l|}
\hline Approaching Degree i.e. $\boldsymbol{\gamma}$ & State of Transformer \\
\hline$\gamma \in[0.90,1]$ & Healthy \\
\hline$\gamma \in[0.80,0.90)$ & Abs. Normal \\
\hline$\gamma \in[0.70,0.80)$ & Normal \\
\hline$\gamma \in[0.60,0.70)$ & Slight fault \\
\hline$\gamma \in[0.50,0.60)$ & Middle fault \\
\hline$\gamma \in[0.40,0.50)$ & Serious fault \\
\hline$\gamma \in[0.33,0.40)$ & Critical \\
\hline
\end{tabular}

\section{ABSOLUTE AND RELATIVE SCALING OF TRANSFORMERS}

Industrial standards are compared with the test samples in absolute scaling. Hence synthetic degree of incidence is used to compare the test samples with three caution levels of gases specified in IEEE/IEC guide. However, relative scaling involves comparison of data without any standard model.

\subsection{Grey Methodologies}

Both the scaling techniques are further checked using GIA and GRA, employed on key gas set of 281 samples. The classification using synthetic degree of grey incidence on three caution levels as well as absolute scaling using caution level-1 are displayed in Table 6.

Table 6: Absolute Scaling using SD (GIA)

\begin{tabular}{|l|l|}
\hline Absolute Scaling & GIA Method \\
\hline Healthy & 03 \\
\hline Abs. Normal & 20 \\
\hline Normal & 63 \\
\hline Slight fault & 86 \\
\hline Serious fault & 109 \\
\hline \multicolumn{2}{|l|}{ Total No. of Transformers $=281$} \\
\hline
\end{tabular}


Table 7: Relative scaling using AD (GRA)

\begin{tabular}{|l|l|l|l|}
\hline $\begin{array}{l}\text { Degree of } \\
\text { Incidences }\end{array}$ & $\begin{array}{l}\text { Caution } \\
\text { Level-1 }\end{array}$ & $\begin{array}{l}\text { Caution } \\
\text { Level-2 }\end{array}$ & $\begin{array}{l}\text { Caution } \\
\text { Level-3 }\end{array}$ \\
\hline Absolute & 137 & 62 & 82 \\
\hline Relative & 30 & 46 & 205 \\
\hline Synthetic & 94 & 86 & 101 \\
\hline
\end{tabular}

The test samples are normalized first and then find the approaching degrees (AD) of every sample by GRA procedure. The classification of transformer samples is displayed in Table-7 as above. The results of grey methods for absolute and relative scaling are further examined using ANFIS and NF tool.

\subsection{Absolute Scaling using ANFIS and NF}

Subtractive clustering option of ANFIS is selected for natural groupings of data which produces a concise representation of a system's behavior from input-output. A Sugeno-type fuzzy inference system is generated by selecting genfis2, builds upon the subclust function. Normalized input of seven key gases and the corresponding GIA outputs from synthetic degree (caution level-1) are considered for investigation. The subtractive clustering structure and generated FIS is shown in fig. 1 and 2 respectively.

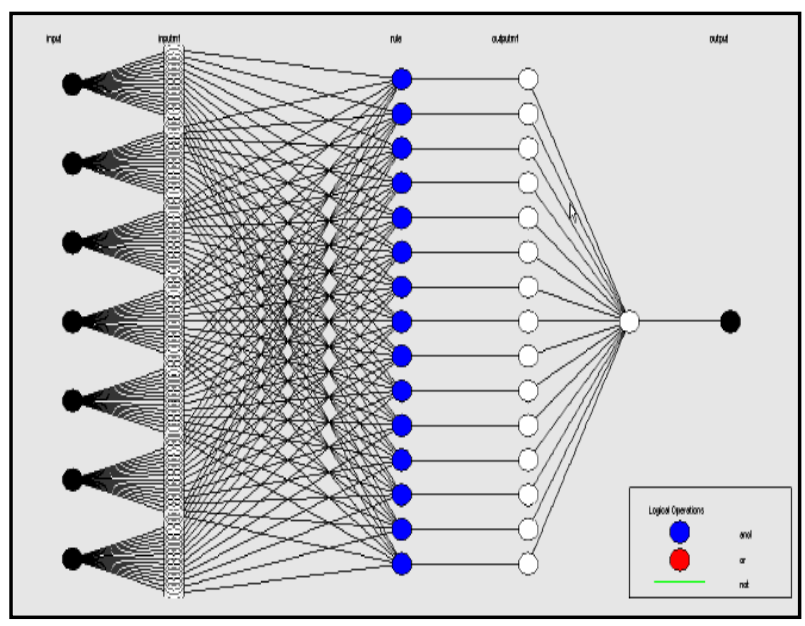

Fig.1: Structure for GIA output

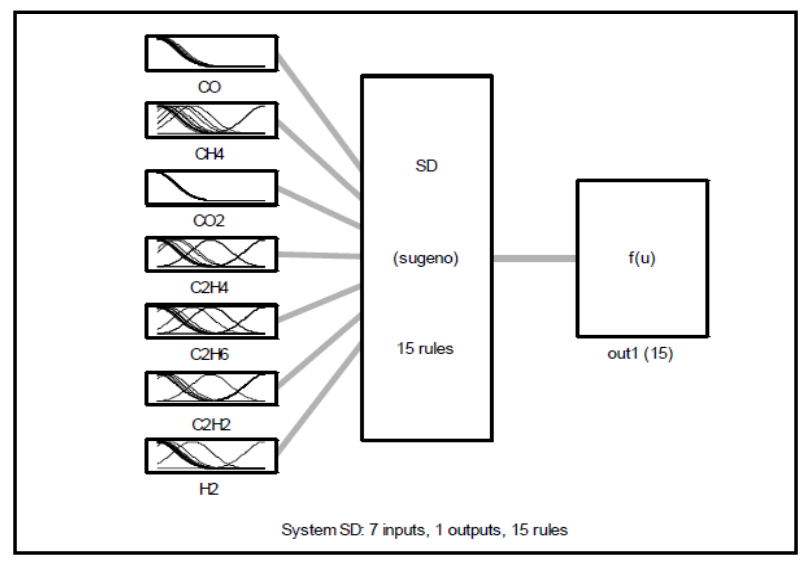

Fig.2: FIS for Synthetic degree (caution level-1)

A neural network maps between a data set of input variables and a set of GIA output. A two-layer feed-forward network with three hidden neurons fit this multi-dimensional mapping problem. The network is trained with Levenberg-Marquardt back-propagation algorithm. The numerical outputs from
ANFIS and NF for absolute scaling are represented using stem plot as shown in fig. 3 and 4 respectively.

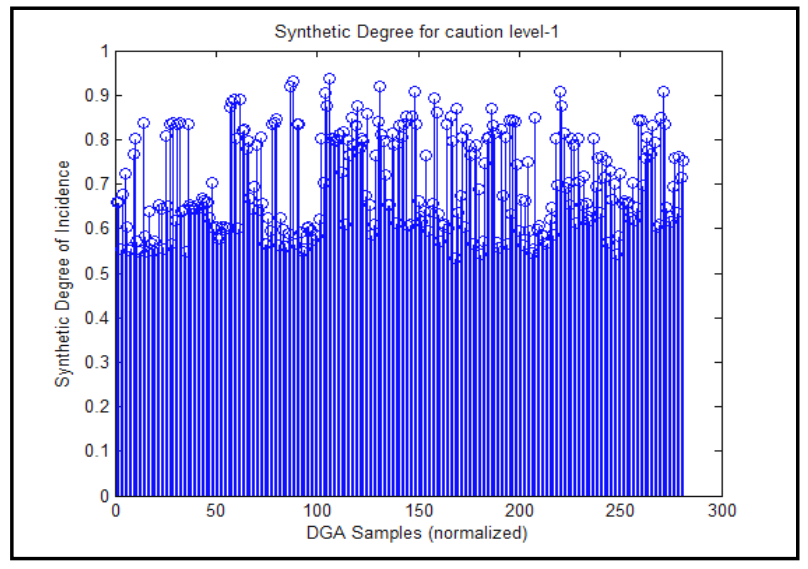

Fig. 3: ANFIS output

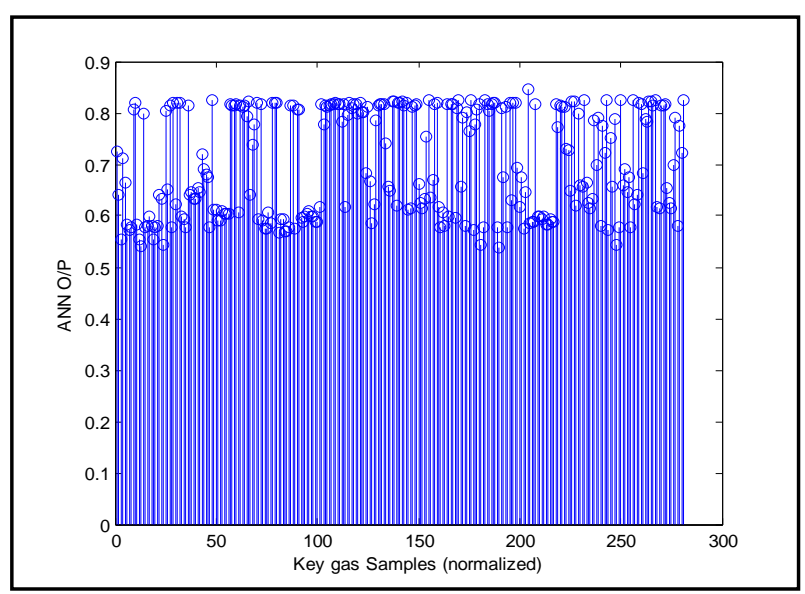

Fig. 4: ANN output

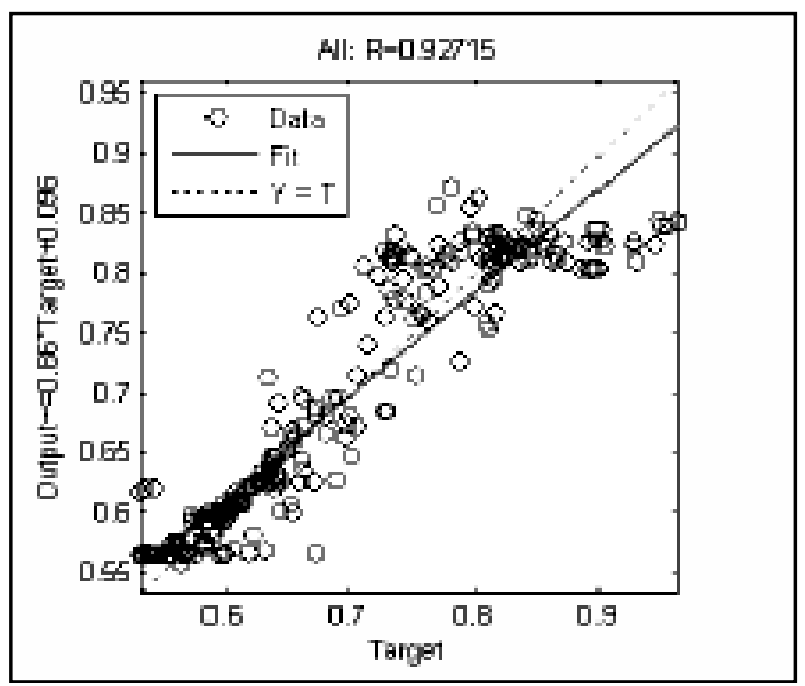

Fig.5: Best fit for SD (caution level-1)

The correlation of 0.9271 is observed for caution level-1. However, the best ANN outcome for synthetic degree on first caution level observed in net_218 at minimum error of $4.825 \times 10^{-4}$. The regression result of the network for synthetic degree is shown in fig. 5 and classification in fig. 6. 


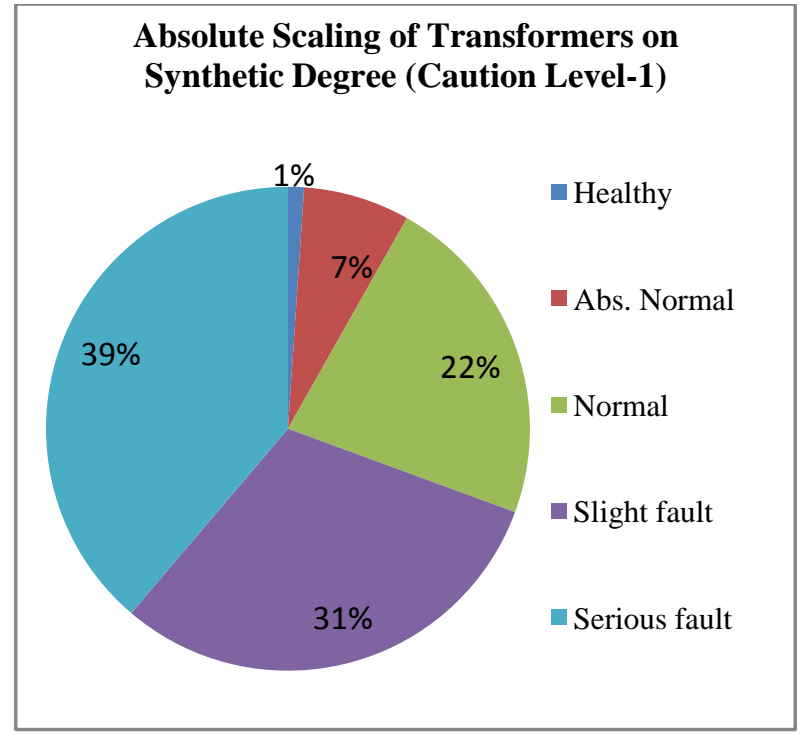

Fig.6: Health categorization

\subsection{Evaluation Using Relative Scaling}

Adopting the same approach for the relative scaling, the ANFIS and NN are used for GRA. The input-output data set of GRA attempted for subtractive clustering and neural network fitting. The structure and FIS generated is displayed in fig. $7 \& 8$ respectively.

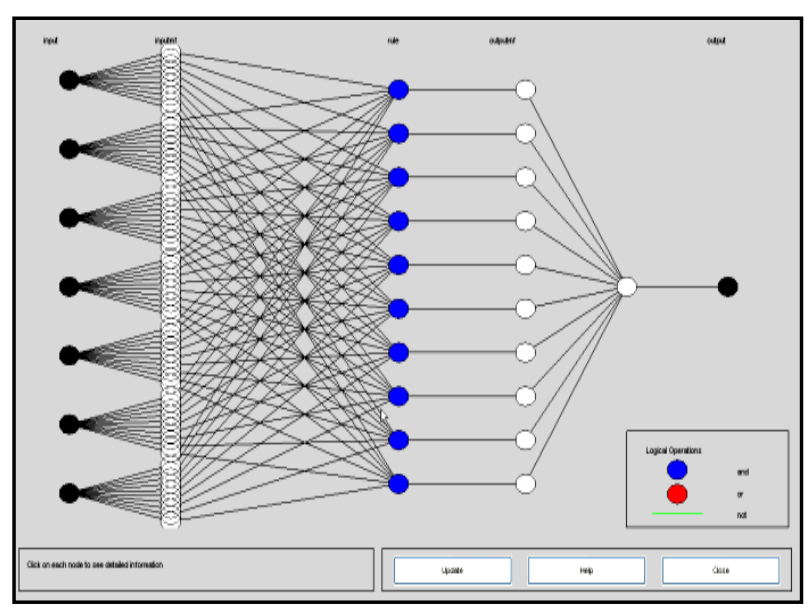

Fig.7: Structure for GRA output

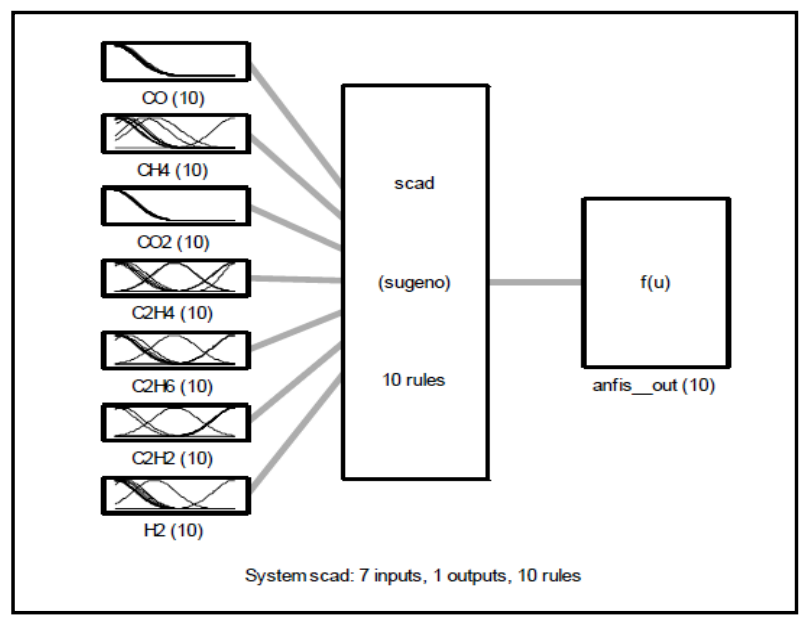

fig.8: FIS for Synthetic degree
The numerical outputs of ANFIS and NF for relative scaling are represented in the following figures (fig.9 \& 10).

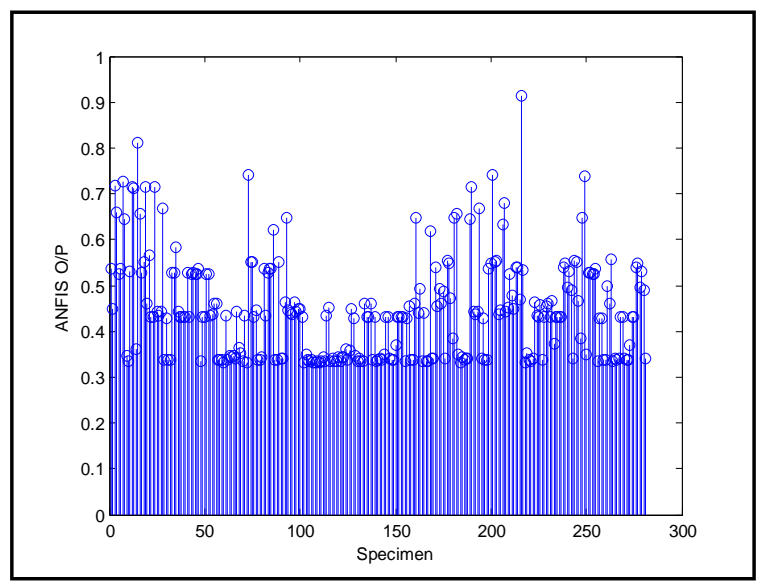

Fig. 9: ANFIS output

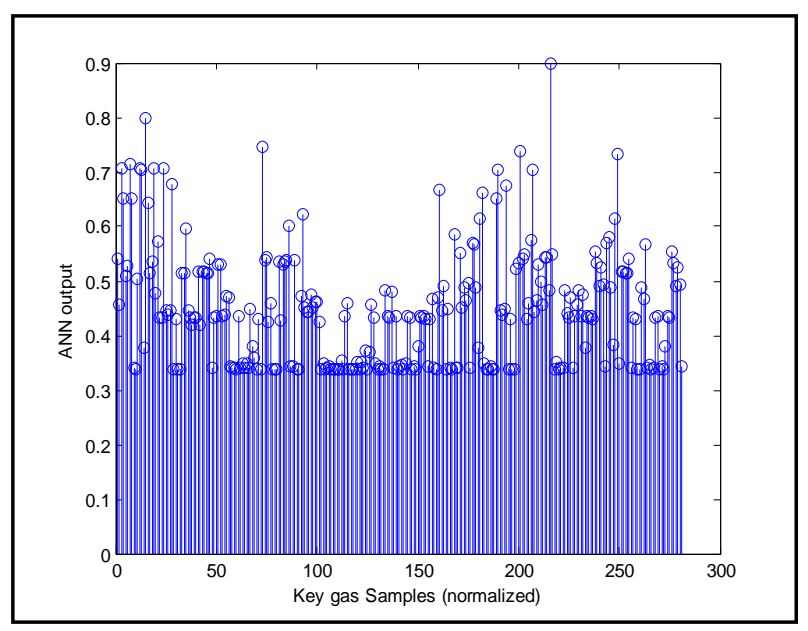

Fig. 10: ANN output

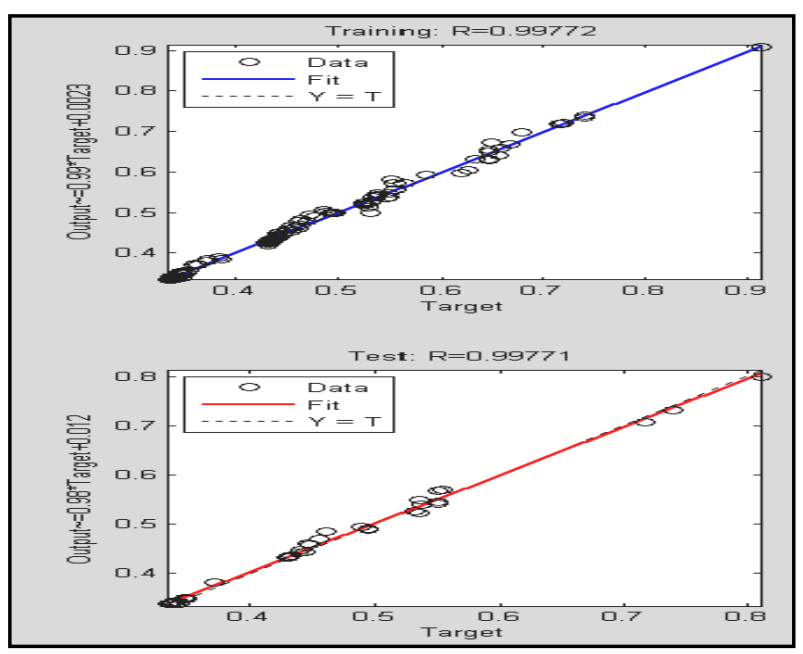

Fig. 11: Best fit for GRA data

The results of the network have found in net 162 shown perfect overall liner relationships of 0.99727 for the given data, same is displayed in fig. 11 as above. The fig. 12 shows health-wise classification by adopting the relative scaling. 


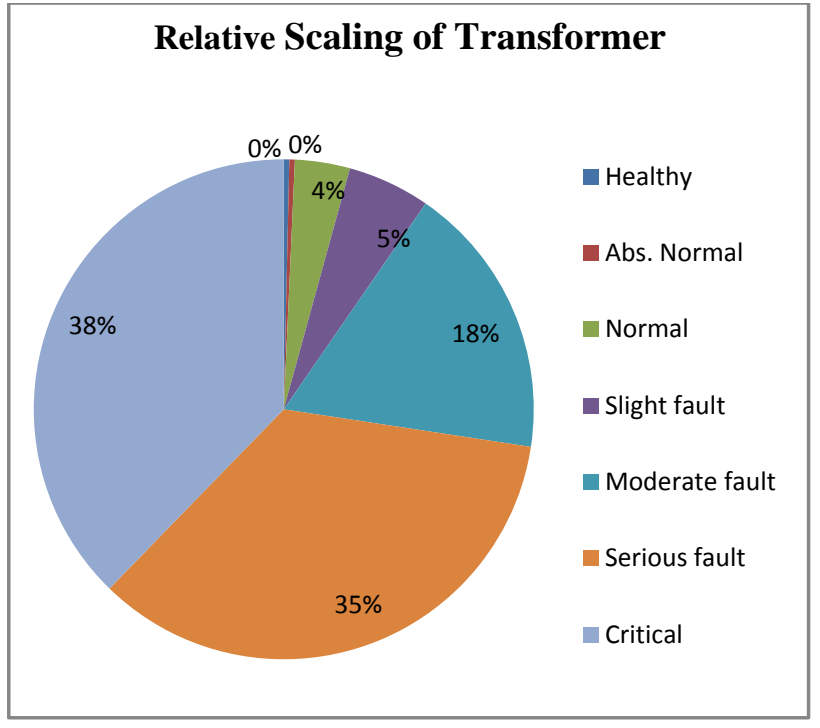

Fig.12: Health categorization

\section{CONCLUSIONS}

The phenomenon of dissolved-gas-in-oil represents the partial information of a gigantic system like power transformer. The analogy of partial information from grey system theory is utilized here to compute the health index of transformers. Two methods from grey system theory i.e. GIA and GRA are introduced for state assessment. These methods have been demonstrated using key gas samples to calculate their health index. Selecting the resolving coefficient of 0.5 for GIA as well as GRA gives straight forward categorization about transformer health with five and seven grades respectively. These intervals with qualitative notation about the health are further used for absolute and relative scaling of transformers. The benchmarking of GIA and GRA methods are further testified by applying the subtractive clustering option from ANFIS and with network fitting tool of ANN. The outcome of these soft computing techniques has shown better co-relationship for relative scaling compare to absolute scaling. The absolute and relative scaling models presented by means of grey methodologies have shown a certain degree of success in assessing the health condition of working transformers on qualitative and quantitative basis.

\section{REFERENCES}

[1] Dragan Kovacevic, Jelena Lukic, Dragana NaumovicVukovic, Slobodan Skundric; Institute Nikola Tesla, Belgrade, Serbia, "Integrated Management system for Testing, Monitoring and Diagnostics of Power Transformer Insulation", XIX IMEKO World congress on Fundamental and applied Metrology, Lisbon, Portugal, sept. 6-11, 2009, pp. 1350-1353.

[2] Mladen Banovic, Josip Butorac, "Automatic Diagnosis of Power Transformers Status based on Dissolved gas Analysis-First level of Diagnosis using VAC and VSC Interface Methods", XIX IMEKO World congress on Fundamental and applied Metrology, Lisbon, Portugal, sept. 6-11, 2009, pp. 1359-1364. Instrument Transformer Condition Assessment and Diagnostics, CEATI Report No. T033700-3024, April 2005.

[3] Setayeshmehr, A. Akbari, H. Borsi and E. Gockenbach, "A procedure for diagnosis and condition based maintenance for power transformers," in proc.
Conference Record of the 2004 IEEE International Symposium on Electrical Insulation, 2004, pp. 504-507.

[4] A.N.Jahromi, R. Peircy, S. Cress, J.R.R.Service and W.Fan, "An Approach to power Transformer Asset Management using Health Index," IEEE Electrical Insulation Magazine,Vol.25,No.2, 2009,pp.20-34.

[5] Ahemed Abu-Siada, M. Arshad and S. Islam, "Fuzzy Logic Approach to Identify Transformer Criticality using Dissolved Gas Analysis", Power and Energy Society General meeting 2010 IEEE, 25-29 july 2010, pp.1-5.

[6] Hydroelectric Research and Technical Services Group "TRANSFORMER DIAGNOSTICS- Facilities Instructions, Standards, and Techniques", US Department of the Interior Bureau of Reclamation, Volume 3-31, June 2003.

[7] Toronto Hydro-Electric System Limited, 2010 Asset Condition Assessment Audit, Kinectrics Inc. Report No: K-015466-RA-0001-R01; July 23, 2010.

[8] Norman Field, Stan Cramer, Stephen Antosz, "Condition-Based Ranking of Power transformers", Weidmann- ACTI Conference, Las Vegas, Nevada, November 8, 2002.

[9] IEEE Engg.soc., ANSI/IEEE std.C57.104, 2008 "IEEE Guide for the interpretation of gases generated in oil immersed transformers", (Revision of IEEE std.C57.1041991), pp CI-27, 2009

[10] IEC 60599, "Mineral Oil-Impregnated Electrical Equipment in service-Guide to the Interpretation of Dissolved and free Gases Analysis”, Edition 2, 1999.

[11] Wang Z., Liu Y., Griffin P.J., "A combined ANN and expert system tool for transformer fault diagnosis" IEEE Trans. Power Delivery vol.13(4),1998, pp. 1224-1229.

[12] Zhan-Li Sun,Kin-Fan Au, and Tsan-Ming Choi, "A Neuro-Fuzzy Inference System Through Integration of Fuzzy logic and Extreme learning Machines" ,IEEE Trans. On Systems, Man, and Cybernetics-Part B: CYBERNETICS,Vol.37,No.5,2007,pp.1321-1331.

[13] Balint Nemeth, Szilvia Laboncz, Istvan Kiss., "Condition Monitoring of Power Transformers using DGA and Fuzzy Logic", 2009 IEEE Electrical Insulation Conference,Montreal,QC,Canada,31 May-3 June,2009.

[14] Rui-rui Zheng , Ji-yin Zhao , Bao-chun Wu, "Transformer Oil Dissolved Gas Concentration Prediction Based on Genetic Algorithm and Improved Gray Verhulst Model", International conference on Artificial Intelligence and Computational Intelligence, 2009. AICI'09, pp. $575-579$.

[15] Sikun Yang, "Application of Grey Target Theory for Handling Multi-criteria Vague Decision Making Problems",2008 ISECS International Colloquium on Computing, Communication, Control and Management, 3-4 Aug. 2008, pp 467-471.

[16] Lin $Y$, Liu $S F$., "Solving problems with incomplete information: A grey systems approach", Advances in Imaging and Electron Physics, published by Elsevier, Oxford, UK, 2006, pp. 77-174.

[17] Li $Q X$, Lin $Y$., "The basic architecture of grey system theory", Proceedings of the Conference on Management in China, Lanzhou, China, 2010, pp.158-163. 
[18] Song Bin, Yu Ping, LUO Yun-bai,et al. "Application study on fault diagnosis of transformer by gray relational analysis," Electric Power Automation Equipment, vol. 23, April. 2003, pp. 64-67.

[19] Jiang Yanjun, Ni Yuanping. "Fault Diagnosis Method of Transformer Based on Rough Set and Support Vector Machine," High Voltage Engineering, vol. 34, August. 2008, pp. 1755-1759.

[20] Dong Lixin, Xiao Dengming, LiuYilu., "Insulation fault diagnosis based on group grey relational grade analysis method for power transformers", Journal of Southeast University, vol. 21, June. 2005, pp. 175-179.

[21] Li Jianbo, Zhao Jiyin, Zheng Ruirui., "Power Transformer Fault Diagnosis Based on Comprehensive Correlation Analysis," Journal of Jilin University (Information Science Edition), vol.26, Jan.y2008 , pp. 62-68.
[22] Fu Mingfu, Xie Mingxiang, Rao Hong, "Fault Diagnosis of Suction Fan Based on the Synthetically Relational Analysis", China Mechanical Engineering, vol.18, October 2007, pp. 2403-2405.

[23] Liu $S$ F, Lin $Y$., "The role and position of grey systems theory in science development", Journal of Grey Systems, 1997, pp.351-356.

[24] Liu S. F., and Lin, Y., "Grey Information: Theory and Practical Applications”, Springer-Verlag, London, 2006.

[25] Jianpo Li, Xiaojuan Chen, Chunming Wu; Information Engineering College Northeast Dianli University Jilin, China, "Power Transformer State Assessment Based on Grey Target Theory" 2009 International Conference on Measuring Technology and Mechatronics Automation, IEEE Computer Society, ICMTMA-2009, pp. 664-667. 